\title{
Como abordar uma instalação de domótica KNX para uma moradia?
}

\section{Generalidades}

A domótica pode ser entendida como o controlo automatizado das instalações técnicas existentes num edifício.

No caso concreto de uma habitação, utilizando a tecnologia KNX podemos controlar, por exemplo:

- iluminação;

- estores e persianas;

- $\quad$ sistemas de segurança;

- $\quad$ gestão de energia;

- sistemas de aquecimento, ventilação e ar condicionado (AVAC);

- controlo remoto;

- controlo áudio/vídeo;
Como hoje em dia, aspetos como a segurança, eficiência energética, conforto e comunicação são cada vez mais uma exigência dos proprietários/utilizadores dos edifícios, não faz sentido continuar a abordar a execução de instalações elétricas do tipo convencional, sistemas de AVAC, alarmes e outros, sem que estes comuniquem entre si.

Assim, justifica-se a apresentação ao cliente das instalações elétricas apoiadas numa solução de domótica KNX, o que possibilitará a integração e comunicação daqueles sistemas.

No caso concreto de uma moradia unifamiliar o estudo técnico-económico de uma instalação de domótica, passa inicialmente pelas seguintes fases:

- definição com o cliente de quais as funções pretendidas comandar pela domótica;

- definição dos circuitos de iluminação, por divisão, o que nos vai indicar o número de circuitos por piso e como tal o número de módulos necessários instalar no quadro elétrico do respectivo piso;

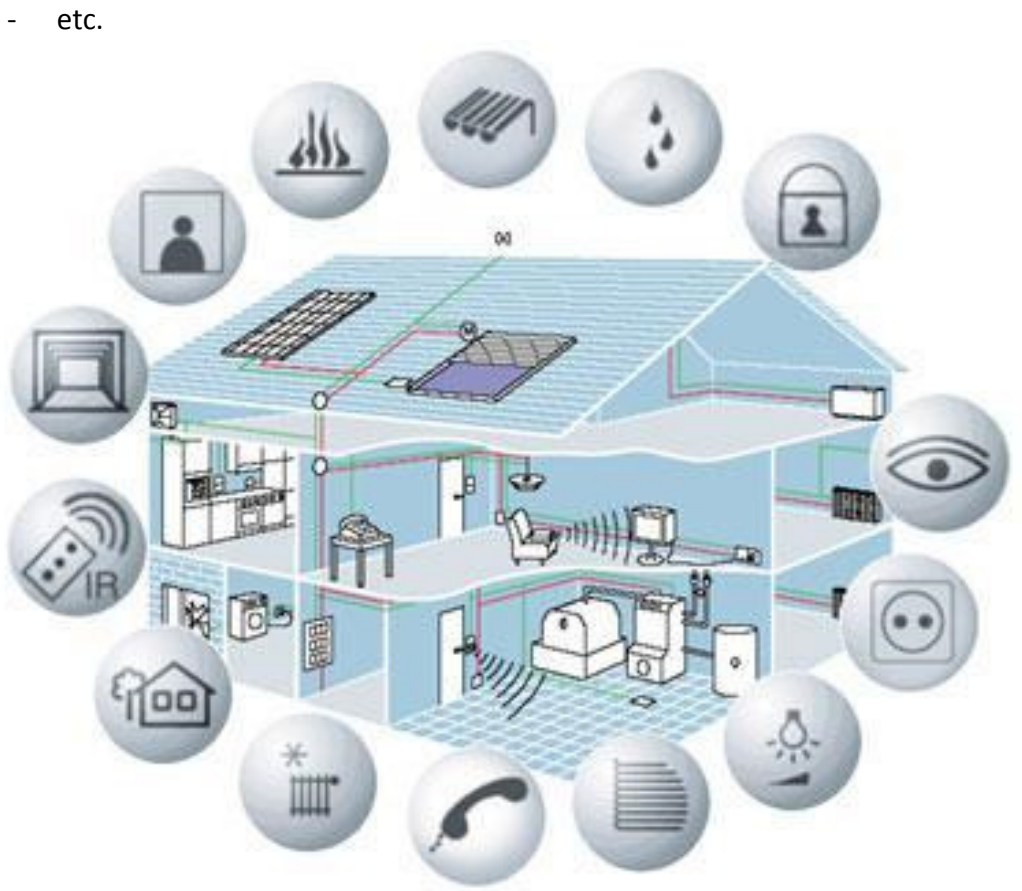

- definição dos circuitos de iluminação que serão comandados por dimmer e como tal o número de módulos necessários instalar no quadro elétrico do respectivo piso;

- definição do número de estores / persianas, por piso e como tal o número de módulos necessários instalar no quadro elétrico do respectivo piso;

definição do número de teclas / botões por divisão e se estes vão ser de tecnologia KNX ou se se vai optar por uma solução mais económica, com botões de pressão convencionais associado a um módulo KNX; 
Estes aspetos, devem ser entendidos como definições base para iniciar uma instalação de domótica.

Caso o cliente tenha disponibilidade poderão existir outros aspetos a ter em linha de conta, como por exemplo, interação com o sistema de circuito fechado de televisão (Closed-circuit television - CCTV), integração do IPAD para interagir com a instalação de domótica, ...

Como tal, logo à partida, é importante a definição das instalações técnicas a existir para a habitação, sejam elas a instalar de imediato, sejam a instalar no futuro.

Tendo em contas os aspetos atrás referidos e como a tecnologia domótica KNX é sempre ampliável com a integração de novos módulos e/ou com a parametrização de novas funções, convém prever espaço de reserva nos quadros elétricos para a integração destes novos módulos e também convém prever tubagem de reserva de interligação aos sistemas de água e gás (para o comando de electroválvulas), intrusão e também para outros locais estratégicos, como por exemplo para a instalação de uma central meteorológica ou então para a instalação de sondas para medir a luminosidade ambiente.

\section{Estudo de caso: Moradia unifamiliar}

De seguida será apresentada uma instalação real, uma moradia unifamiliar, objeto de instalação de um sistema de domótica, neste caso com recurso à tecnologia KNX.

Para a realização da foi fornecido pelo dono de obra, plantas da habitação, nas quais constava a seguinte informação:

- localização dos quadros elétricos;

- circuitos de iluminação e tomadas a ser comandados pela domótica;

- circuitos de estores a ser comandados pela domótica;

- localização dos botões.

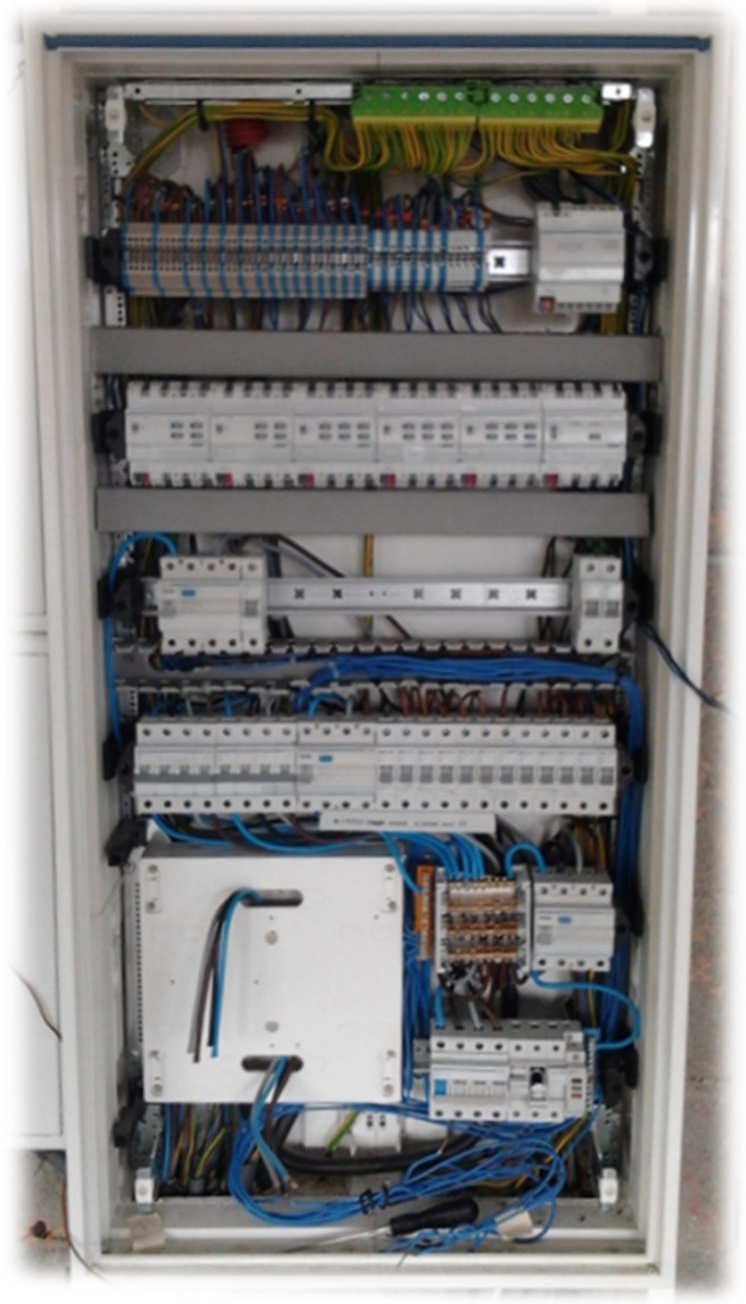

Foi, também, definido quais as funções pretendidas para cada tecla.

Com esta informação, foi possível definir o número de módulos KNX a instalar em cada quadro elétrico e também a quantidade de botões necessários para controlar a instalação.

Para trazer uma maior flexibilidade, funcionalidade e comodidade à instalação, a mesma vai também ser equipada com 3 telecomandos de rádio frequência (RF KNX), com as caraterísticas a seguir descritas:

- telecomando RF KNX de 4 canais: 1un;

- telecomando RF KNX de 6 canais: 1un;

- telecomando RF KNX de 18 canais: 1 un. 
os telecomandos de rádio frequência são emissores de rádio portáteis que funcionam de acordo com o protocolo KNX.

Para que estes telecomandos comuniquem com a instalação de domótica, optou-se pela solução da instalação de um equipamento designado por "Acoplador de Media". Para que os mesmos possam cobrir a maior área possível da instalação, o "Acoplador de Média" foi instalado no piso intermédio da instalação e numa zona central do mesmo.

Esta solução permite o acesso a funções tais como:

- comandos ON/OFF;

- estores/persianas;

- aquecimento;

- comandos temporizados;

- cenários.

Embora representem um custo não negligenciável, a instalação dos telecomandos, permite que a instalação fique mais flexível ao nível do utilizador, pois em qualquer local da habitação, mesmo no exterior, o utilizador tem a possibilidade de controlar o sistema de domótica, o que de outra forma apenas seria possível através dos botões instalados.

A pensar numa maior valia que futuramente pode ser acrescentada à instalação, foi desde já prevista a instalação de tubagem que permita a instalação de um painel tátil, equipamento que o cliente não entendeu prever nesta fase de execução da obra.

Assim, entre o quadro elétrico e uma caixa de suporte, foi instalada a seguinte tubagem:

- um tubo para alimentação;

- um tubo para o cabo de Bus;

- um para interligação ao ATI (cabo UTP4/).
Após a execução da instalação, com a respetiva instalação e cablagem de todos os componentes da mesma, torna-se necessário proceder à parametrização.

Para a parametrização do sistema KNX é utilizado o software ETS (Engineering Tool Software).

A parametrização do sistema é uma tarefa importante e com alguma complexidade, sendo realizada por um técnico devidamente formado e habilitado e que, dependendo da dimensão e complexidade da instalação, pode consumir um tempo significativo.

No momento de receção da obra é entregue ao cliente o ficheiro com a parametrização da obra, de forma a permitir futuras alterações á programação estabelecida.

\section{Conclusões}

A instalação de um sistema de domótica embora comporte um acréscimo no custo inicial das instalações, face à instalação "tradicional", comporta um conjunto de maiorvalias, que, em regra, justificam a sua instalação.

Aspetos como a integração, segurança, comodidade, flexibilidade, funcionalidade, adaptabilidade são significativamente incrementados com a instalação destes sistemas, mas aspetos com a gestão de energia e a eficiência energética também não são negligenciáveis, podendo conduzir a uma redução dos consumos energéticos da instalação e a uma redução dos custos de exploração dessas mesmas instalações.

Assim, o custo total de uma instalação dotada de um sistema de domótica, custo inicial mais custo de exploração, pode ser muito aproximado do custo global de uma instalação tradicional. 